\title{
Research agenda for SMEs in electronic platforms for the European food industry
}

\author{
G.C. Holt, M. Henchion, C. Reynolds, B. Baviera, J. Calabrese, L. Contini, C. Cowan, \\ T. Dowgielwicz, C. Luscher, A. Maraglino, R. Prugger and R. Tononi
}

(Author details can be found at the end of the article.)
The authors acknowledge the support of the European Commission through Specific Support Action 00724 e-MENSA "e-Platforms for the European agri-food industry".

\begin{abstract}
Purpose - This paper sets out to provide a consensus position on the potential for the inclusion of small businesses in electronic platforms in the food industry.

Design/methodology/approach - The consensus was derived through a Delphi-type series of questions in an open forum of academics and industrialists across Europe.

Findings - The consensus reached was of the proven benefits of electronic platforms for small businesses and the need for further research to assess how small businesses can incorporate electronic traceability and supply chain management systems into their existing operations.

Practical implications - Electronic platforms are spreading rapidly in the food industry. However, there is some concern that small businesses are not aware of the potential for electronic supply chains such as the potential that electronic traceability offers smaller networks to supply highly demanded food quality attributes such as organic production and regional foods.
\end{abstract}

Originality/value - The paper addresses the highly topical issue of food origin with a new approach to the supply technologies behind the product.

Keywords Food industry, Agriculture, Distribution, Retailing, Communication technologies, Small to medium-sized enterprises

Paper type Research paper

\section{Introduction}

\section{Overview of the European agri-food supply chain}

Consumer expectations shaping the European food industry are for freshness, convenience, and sophistication. Consumers are currently trading both down to low-cost commodities and up to high value premium brands (IBM, 2004, cited in Wysocki, 2005), and are thinking in terms of menus not products. The primary demand for at-home convenience and pre-packed foods that require little preparation for cooking continues, but consumers are looking for inspiration in healthy, exotic and authentic recipes. To service these new demands, information technologies are increasingly required to raise the health, environmental and welfare profile of food relating to - methods of production (such as organic, free range and GM), safe, near-fresh processing methods, and distribution networks ("food miles"). The ability to collect this information and use it to ensure product quality in real-time will provide tangible benefits to the food industry (Wilson and Clarke, 1998).

Greater product quality assurance and rapid identification of problems provide mechanisms for communicating to the consumer the diligence with which the food industry operates. However, the increased demand for product information as consumers continue to gain knowledge and market power is not the only challenge currently facing the agri-food supply chain. Other pressing considerations include increased costs of legal requirements for safety and traceability, cost of waste production, removal and/or recycling and fuel consumption due to insufficient planning, decreased quality of buyer-supplier relationships caused by delays and damaged goods, and lack of effectively trained management personnel. 
Concentration in European retailing has increased sharply, especially in continental Europe. The market share of the top five retailers in 2002 was 69 percent and since this time the sector has seen major acquisitions and US investment. As freight volumes continue to grow, with overall logistics trends predicted of 15 percent increment at European level and 19 percent worldwide, production and warehousing capacity are also likely to concentrate, supply lines to lengthen, and stock-rates to increase. In the longer-term, the basis for competition in the global food system is shifting away from tangible assets toward intangible assets (Boehlje, 1999 cited in Sporleder et al., 2005) and in response; 'value-creating' vertical networks are being spawned (Sporleder and Moss, 2002 cited in Sporleder et al., 2005). Traditional transaction costs are a critical determinant of governance for these supply chains, suggesting that supply chains that seek to share risk and rewards among participants will be increasingly dominated by larger firms at both the buyer and supplier level - leading to more consolidation, particularly at the production end of those industries.

However, although it is commonly accepted that the result of retailer concentration has been downward pressure on farmers, "overall spread data do not indicate a systematic widening of farm-gate retail price in the 1990s as a result of potentially stronger buying power caused by increasing concentration in the food retail sector" (LSE, 2004). Indeed, tightly aligned supply chains are forming at a rapid pace in the agricultural sector. Value creation is accomplished by forming alliances that leverage intellectual property to match unique product characteristics and information technology with under-served markets. Key elements of the success of such niche markets have been delineated (OECD, 1995, cited in Ilbery and Kneafsey, 1998) as follows:

1. Identification and assessment of local resources.

2. Competitive advantage based on local initiative entrepreneurship and partnership.

3. Organizational structure and shared interest.

4. Territorial linkage to landscape, cultural traditions or historic monuments.

5. Advertising to create an image of quality.

6. Information, communication and transport networks.

7. Technical and financial assistance.

8. Regulation measures such as certification of origin.

9. Re-evaluation and periodic review.

But at the same time the transformation to tightly aligned supply chains will introduce new strategic risks that will require additional analysis and skills to manage and/or mitigate (Gray and Boehlje, 2005). Alliance-based chains imply the ability to differentiate products and respond more quickly to market changes than traditional transaction-based supply chains (Sporleder et al., 2005). Moreover, large retailers will further extend their control over the supply chain with the proportion of retail sales bypassing conventional shops and being delivered directly to the home increasing significantly, and the outsourcing of value-adding logistics services, particularly information management and product customization (MacKinnon and Forster, 2000). Thus, the frictionless marketplace is characterized by a renewed emphasis on the individual shopper; retailers have come full circle from the neighborhood grocer of the pre-development phase to the technology systems that allow new "intimacy" with customers. But with this new agency for the transfer of goods and services from manufacturers to shopper, warehousing becomes redundant (Terbeck, 1999, cited in Wysocki, 2005).

Structurally, the agriculture sector is the weakest link in the European agri-food chain being dependent on high labor intensity with few information and communication technologies (ICTs). To optimize the agri-food supply chain, changes in the agricultural sector are required in many countries, particularly South and East Europe where land tenure is fragmented, and farmers still use traditional means of production and have limited understanding of market demands. Steps to redress this situation include the 
comprehensive and accessible interactive market information website operated by the Croatian government but equally, new models are required to develop food chains from an alternative, rural development perspective, in which locality provenance, harvest and slaughter, can be systematically employed as a source of customer value (Forsman and Paananen, 2002).

\section{The potential role of e-platforms in the agri-food chain}

ICTs improve the products and services companies offer and allow new forms of partnership between suppliers and consumers. Europe's Single Market was created by eliminating barriers for companies wanting to conduct business across national boundaries, thus enabling an increasingly competitive trading block within a globalized economy. But despite the free trade area, European legislation could not eliminate the barrier of geographical distance. E-business therefore helps eliminate the final barrier to free trading, allowing companies worldwide to trade from a single website.

Internet commerce is based on the sharing of business information and conducting transactions and maintaining relationships by internet-based technologies. Electronic trade systems are a mechanism which brings the buyer and seller together in many different forms but which generally reduces transaction costs (Kaplan and Sawhney, 2000, cited in Brand et al., 2003). Electronic marketplaces naturally support products with search qualities over products with a high level of experience and credence qualities such as organic. Firms selling search foods of low tangibility have a natural advantage in e-commerce but small firms should not be discouraged because there are good prospects for enhanced competitiveness and improved business performance regardless of product characteristics (Poon, 1999). Plus, the internet can turn credence qualities into search qualities by providing a high degree of information to the consumer through the combined media of graphics, sound, and text (see for example www.petersfarm.com).

\section{What is a food chain electronic platform (e-platform)?}

An e-platform may be defined as a software infrastructure (coordinated set of computer programs) on which applications (other programs that provide specific functionalities for the user) can be installed, so that the applications communicate and support the end-user in the performance of complex tasks through a coordinated set of functionalities. A food industry e-platform is thus:

- A software system to collect, manage and store data for the validation and verification of food safety and quality standards, thereby contributing to a framework for the harmonization of quality assurance protocols along the entire European food supply chain.

- A network connecting stakeholders via computer interfaces capable of coordinating communication within agri-food supply communities, sharing information between players in a supply chain, and maintaining security of information circulating in the platform.

Component concepts of collaborative electronic supply chains are:

- Harmonizing quality assurance procedures and standards within commercial and other stakeholder alliances and between different electronic communications networks, whilst.

- Protecting the right to privacy of commerce and European citizens.

Achieving these goals will require both new technologies and new sets of skills throughout the workforce. Specifically highlighted for action is the need to establish an e-business support network to strengthen and coordinate European SMEs by raising awareness of the real benefits to be obtained by implementing advanced e-business solutions (http://europa. eu.int/information_society/eeurope/2005). 


\section{Methodology}

To encircle and define the most important aspects concerning e-platforms, transnational discussion forums involving academic experts and non-government and private food chain players, aimed at identifying and evaluating technologies for supply chain management, were set up. Dialogue regarding the potential for implementation of e-platforms in the food industry was facilitated with specific remit to encourage the participation of small and micro businesses.

Expert consultation was coordinated in three food chain sectors (production, processing, and distribution-retail), by ten organizations within the e-MENSA partnership representing stakeholder interests in food industry development. The Delphi qualitative research principle was followed, "allowing a group of experts to participate jointly in defining and analyzing complex issues where information is fragmentary" (Kretzschmar, 2005). The survey $(n>50)$ was conducted in two phases; first, between June 2005 and March 2006, through sector-specific expert discussion forums and second, between March-May 2006, through an integrated food chain expert discussion forum, culminating in a policy summary delivered by the e-MENSA partnership to the European Parliament in June 2006. Both phases of the survey consisted of both a physical one-day workshop and a web-based open forum using successive rounds of information gathering and feedback (Figure 1).

\section{Background}

\section{E-platforms in operation in the food industry}

A proportion of product information on origin and integrity is required by the EU General Food Law, which came into force on 1 January 2005. The market for traceability platforms has subsequently become much more active but the key problem dogging Europe-wide traceability is the incompatibility of different platforms used by different actors in different countries. The recently EC-funded e-Fruitrace (www.efruitrace.com/), on which information can be exchanged up and down the food chain from anywhere in the world, overcame the hurdle by unifying various tracking systems. Because e-Fruitrace is compatible with existing traceability solutions, the investment required from agricultural cooperatives, processors and distributors is small compared to the cost of implementing new systems.

Other examples of existing e-platforms include internet markets GlobalNetXchange, WorldWideRetailExchange, Dansk vegetable auction, and other technologies used at retail

Figure 1 e-MENSA specific support action (SSA) expert discussion

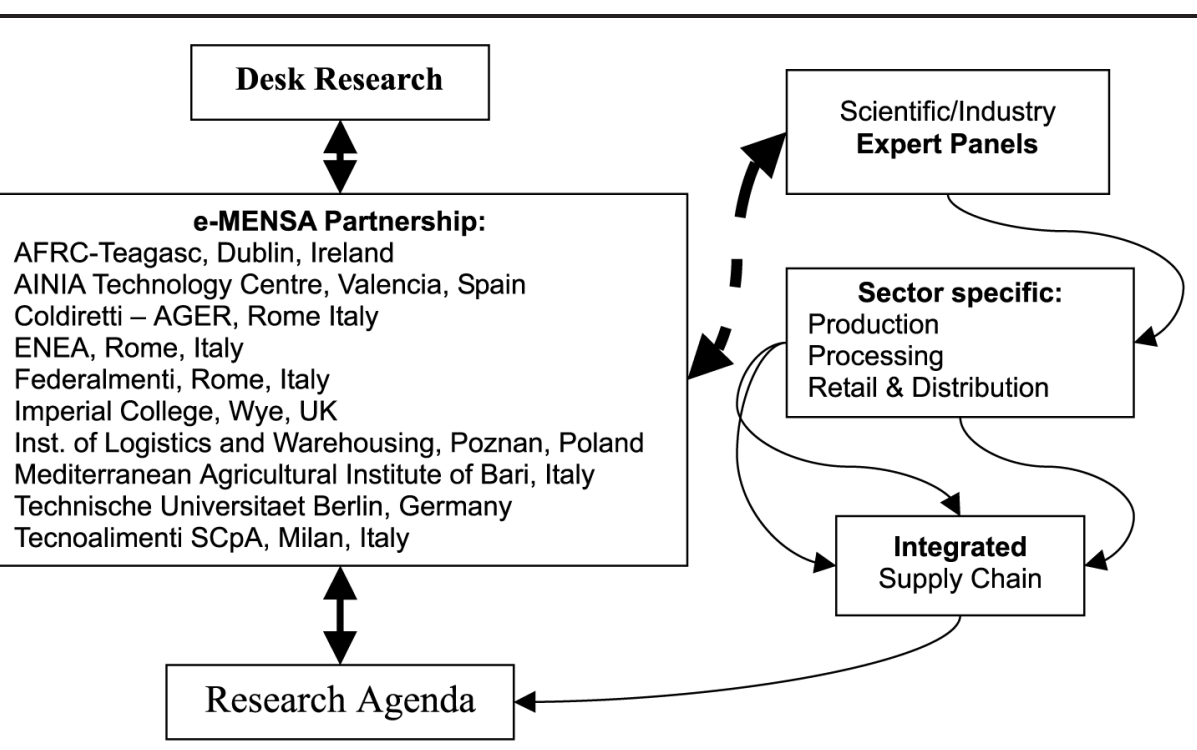

VOL. 9 NO. 32007 foresight $\mid$ PAGE 45 
www.fmi.org/media/bg/supermarkettechnologyfirsts.htm. AFORO Thematic Network Provides an implementation model to enable the full participation of agri-food industries in the digital economy within the next five to ten years. Partners are currently in the process of commercializing the system among agricultural cooperatives and through regional governments and institutions that are active in the sector www.aforo.net/entradaingles. $\mathrm{htm}$. Examples of functions of e-platforms in operation include: JS Sainsbury's Partnership in Fresh Food, providing the following services:

- product tracking and tracing;

- greater transmission of market signals; and

- sharing information on best practices and technical specifications.

In the Irish food industry, two examples are:

1. the Seafood Producers Group providing:

- market information;

- information on production volumes and required times (EDI); and

- greater control of the supply chain (www.ispg.ie; http://suppliers.econ.upatras.gr).

2. The Irish Food Board, Bord Bia, providing:

- statistical information on cattle, pig, lamb traders in major markets; and

- Irish specialty food purchase (www.bbextranet.ie).

However, in South and East Europe there is poor vertical integration in the agri-food chain and so far little attention has been paid to existing decentralized supply chains (i.e. controlled by independent members rather than a large enterprise or managerial hub) made up of SMEs, which are typical in the South and East European agri-food sectors. No strategic plan has emerged to deploy e-platform architectures to drive development for SMEs towards supply chain management issues. Through e-MENSA, a new management model, the small-medium enterprise chain (SMEC) model (incorporating SCOR, CPFR and the business process management system for automatic life-cycle management of collaboration processes - for further details contact R. Tononi) was used to illustrate the potential for higher levels of e-platform collaboration and to cope with the needs of smaller scale supply chain members. The SMEC model replaces traditional supplier-client relationships with strategic ICT-supported partnerships, demonstrating the complexity of processes required for collaboration made possible by the model (Figure 2).

\section{Analysis}

The following sections highlight the consensus views of the first, the sector-specific, discussions, and following this, the discussion presents further insights provided through the integrated food chain discussion.

\section{Primary production}

As the first link of the food chain, farmers influence the safety and quality of food but many farmers in Europe have small farms and are not members of a producer organization. These farmers perceive a great disparity in the terms set by retailer pricing policy and lack capital to invest in the cultural change sweeping the agricultural sector and favored by major retailers, to:

- define quality standards (such as globally used British Retail Consortium standards including EurepGAP, and other retailers' own production standards, such as Tesco's Nature's Choice); and

- call for the certification of quality standards.

From the e-MENSA production discussion, it ensued that food chain leadership is deemed necessary whether led by retailer, producer or supply chain manager, but there is a strong mistrust of the rest of the food chain among producers that presents a major cultural 

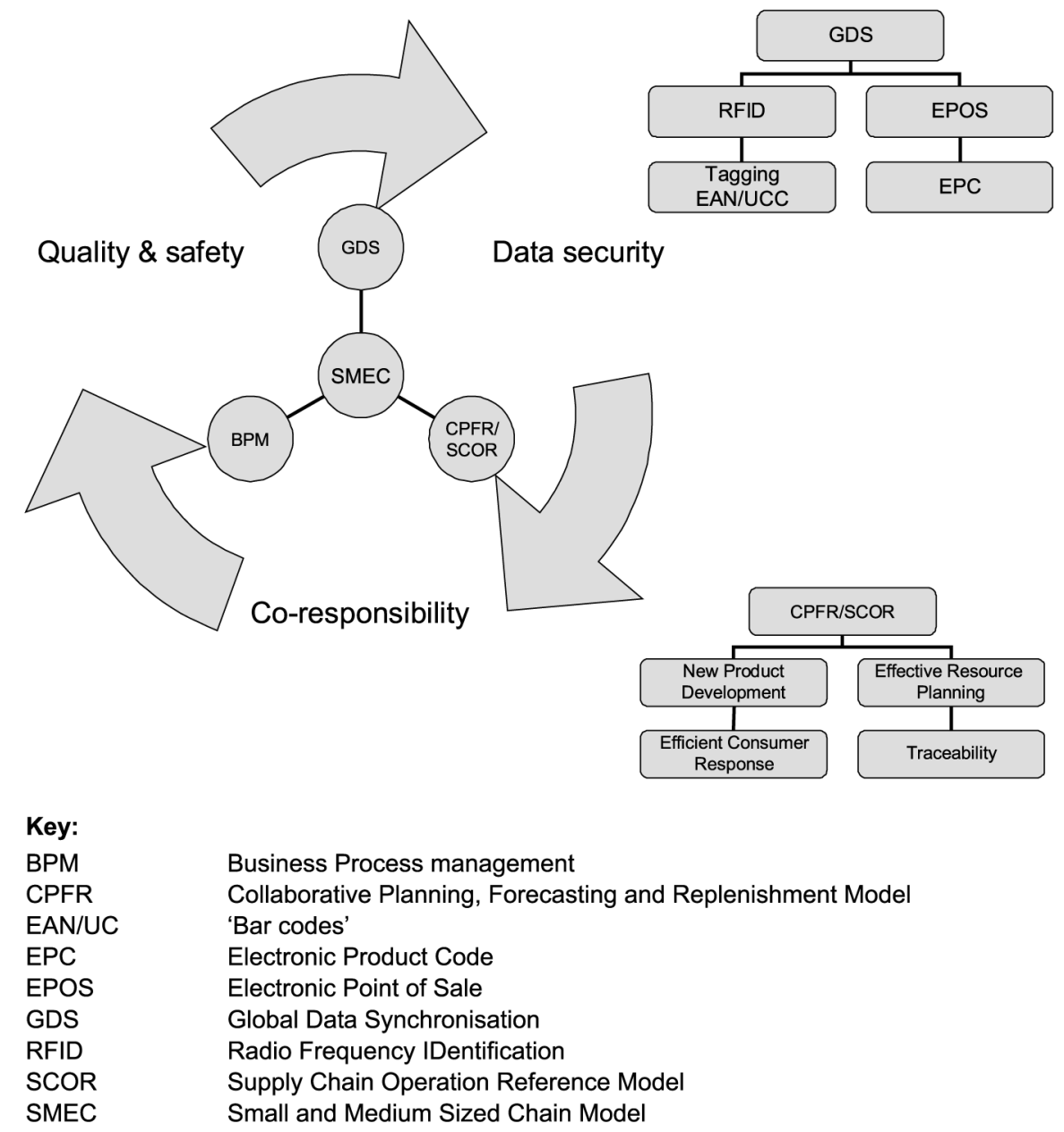

obstacle to vertical collaboration. It is necessary therefore to encourage cultural change before technical innovation through the harmonization of food supply chain norms between countries and where feasible, the relocalization of farmers. Future challenges include linking the innovation of typical, traditional and authentic product attributes to production area and market capacity. Further research is imperative therefore to identify the benefits that farmers and retailers of these typical products gain from using an e-platform and whether or not the e-platform can provide a virtual marketplace only or an interactive consumer-producer information resource.

\section{Processing/manufacture}

Trends in the food market indicate a duality between:

1. Regional identification, demand for organic methods and fresh or minimally-processed foods with consumers highly motivated to receive traceability and other information.

2. Global identification with and for cheap, processed foods and consumers characterized by growing rates of extreme obesity.

Overall the food industry structure is characterized by a high percentage of SMEs, strong global brands, excess production combined with a high presence of low-tech farming, and a competitive economic environment. Retailers are large and dominant, demanding low prices and high quality. Prices and margins have been kept low and although quality 
remains high there has been consistent under-investment in innovation in the processing sector. E-platforms represent a positive step towards improved quality and safety assurances, and are likely to facilitate access to market for SMEs through the sharing of resources, but in order for these to be effective several conditions need to be met, namely:

- a dominant platform player is involved;

- short-term economic benefits are visible; and

- the only mandatory information shared is that required to comply with European legislation.

And finally, to reach the stage where such platforms could be implemented, urgent R\&D considerations include ensuring the compatibility of data system interfaces and speed of data exchange and, in processing technology, improved monitoring for complex processes, in particular liquids.

\section{Distribution/retail}

Trust and collaboration are essential for e-platform establishment. Future challenges for the use of e-platforms in retail and distribution are dependant on the type of ownership model used - this could include, profit-based, institutionally-support or not-for-profit. Real net cost-benefits defined in financial terms must be evident in order for any player to buy-in to the e-platform. Allocation of costs across the platform must be established based on criteria established by a platform leader, or in the case of decentralized platforms through consensus. However, in large volume markets, retailers are already the chain captain and smaller organizations have less ICT capability or skills-base to lead. Alternative e-platforms involving a more cooperative approach may only be possible in new initiatives creating alternative routes to market.

Clearly, it is necessary to identify all associated net benefits and costs of sharing and receiving information. Privacy of information exchanged and security of data depends on the type of information/data to be exchanged and a common strategy. It was considered unrealistic however, and questionable whether necessary, for the platform to achieve a uniform management strategy across all parameters of the supply chain. Nevertheless, there is undoubted advantage in a collaboration strategy to tackle food safety compliances and this could include a common brand or quality mark. Such an arrangement would allow multi-lateral agreements across the platform to which all partners sign into collectively.

Differing requirements for SMEs depend on the type of e-platform (retailer led or alternative route to market). As larger players dominate the chain the main barrier for SMEs is not technological but absorption capacity. Small and micro enterprises may be forced into alternative-routes-to-market e-platforms in order to survive. To assure that small enterprises have the capabilities for participating in e-platforms, a working pilot case study should be set up to act as a demonstration of this type of operation and encourage adoption amongst the SME sector.

\section{Discussion}

\section{Supply chain}

Agriculture is the weakest sector; in many countries producers have little decisional or policy independence. Retailers are the strongest actors with sophisticated information resources but farmers blame retailers for low prices and too much control over SMEs and yet at the same time fear losing retailer business. In Italy, there is a lack of producer and retailer international competitiveness and in the south, farmers lack the capacity to cooperate. There are some producer cooperatives but few processing or retail-only coops. The separate nature of these smaller players makes their potential difficult to enhance. Likewise, in post-communist countries trust will take time to establish and to encourage farmers into associations, demonstration of the effectiveness of cooperation will be needed. In north Europe competitiveness hinders cooperation and it was considered better to develop the 
competences of individual producers, for example many producers have the skills to produce special varieties, rather than to introduce an additional layer of bureaucracy through associations.

The real dictator of the supply chain is consumer demand. Consumers want choice not conformity but policy is still mainly oriented to volume agricultural production. This conflict could partially be solved by supplying higher quality because in the long run only high quality will survive on developed food markets. Specific consumer information needs were identified as:

- Agriculture - origin, methods, agrochemicals, environmental toxicity, animal welfare, livestock disease history, harvest date, post-harvest transportation and storage.

- Logistics - transportation and storage to retail.

- Traceability - underpinned by universal standards including EurepGAP, HACCP and maximum residue levels.

- Processing - methods, artificial enhancers, cell-destructive processes.

- Composition - food ingredients, religious and social implications.

- Risk - allergens, GMOs.

- Health - generic positive benefits and specific products (e.g. fruit), nutrients/anti-nutrients (fibre, sat fat), functional claims.

- Functional - distribution and delivery, order number, date.

- Consumer - shop to "prep" transport, handling and storage including use-by date and information feedback, e.g. call center.

\section{Information flow}

The industrial needs for more efficient collaboration within extended enterprises leads to significant demand for resolving the problems of sharing an immense amount of product knowledge, managed as efficiently as possible over the complete product life cycle and over borders (Düsing et al., 2003). Up to now research has paid limited attention to knowledge transfer in dynamic, especially globally-dispersed, entrepreneurial business networks. An appropriate and targeted management of knowledge is a competitive advantage for enterprises that act in cooperative environments and among companies with knowledge-intensive production processes (Forzi et al., 2003).

The level of innovation and strategies for communication between players are weak points in food supply chains, which present serious obstacles to building effective e-platforms. The core problems indicated are companies retaining autonomy, and data security and privacy. On one hand a full set of reliable IT tools guarantees secure data flow but on the other hand there is still a great deal of reluctance to exchange data even within the same supply chain. Information that relates to customers, or is otherwise integral to business success, is highly sensitive.

The level of information available to retailers through barcodes/POS scanning is significantly greater than that available to the processing sector and enables retailers to examine trend data rapidly. Generally, processors are skeptical of retailer willingness to disclose information but also fear losing retailer business. In some countries retailers and distributors exchange demand/forecast information with food processors that offer flexibility in production and some small farmers are diversifying into processing to find new niches. But in wealthier EU markets, some information is transferred upstream. Some multiple retailers are willing to share specific demand information with suppliers, particularly category captains. UK retailers are comparatively willing, whilst German retailers are secretive and in Denmark the Coop is willing to share information but Dansk Group is less so.

E-platforms could create partnerships between the private sector and public research programs. A case study of the impact of ICTs on the competitiveness of SMEs in Wales, UK (Chevanet and Landy, 2003) found that the main link between the success stories was their 
cooperation with research centers or universities. However, in order for an electronic system to be implemented in an organization, the IT instruments must first be understood in terms of the existing business culture. Many of these firms are not only inept at implementing technology-enabled changes but agri-food cultures are also often adversarial in their approach to technical advancement (Thomas et al., 2002). The e-MENSA experts felt that the leading organization of the platform, supported by consent of other member organizations, would have to decide rules for operations, but in reality this presents a huge cultural change for SMEs. There is an immediate need therefore for research into existing socio-technical systems and the most expedient and labor-extensive route to digitalization and harmonization of paper-based systems.

\section{Quality versus supply chain cooperation}

Quality is currently frequently enforced by retailer-imposed standards - to some extent in collaboration with suppliers - and there is little or no dissent that e-platforms can further increase the safety and quality of the food chain through shared and measurable standards. But for the individual participating organization raised standards of quality and safety may not translate directly into short-term benefits to the business, especially if raising standards requires an initial investment in infrastructure, human resources and technology. The challenge for management research lies in demonstrating to the business community that population level nutritional, health and welfare benefits of food technology translate into real cost savings and efficiencies at organizational level.

To achieve this objective, industry-level benefits must be converted into organizational-level performance benefits by creating a link between collaborative supply chain management and improved product quality. Parallel to recent developments in the food industry (see for instance Holt and Henson, 2000) many small scale farmers in South and East Europe still do not understand the value of certification. There is an immediate need for widespread training in the SME production sector relating to ISO, cyclical or total quality management and quality assurance management. To this end, classifications such as the following (Ilbery and Kneafsey, 1998) provide useful frameworks for training.

Objective and subjective indicators of quality products:

- achieving certification by a professional organisation, government or other external body;

- establishing associations either geographically within a region or historically within a tradition;

- ensuring specification of raw materials, methods and ownership; and

- generating attraction by tapping into the subliminal wants of consumers.

\section{Logistics}

Logistics is viewed as a functional part of an organization but there is a lack of careful and consolidated continuous measurement of logistic efficiency (benchmarking) and there is no adequate logistics market to encourage continuous technological innovation. Currently there is a lack of in-house logistics services in small, especially horticultural businesses. For example, commercial data is inaccurate or missing and there are an excessive number of warehouse rejections due to the lack of automated forecasting, and warehouse management and promotion systems. Often suppliers subscribe and publish in more than one data pool and buyers must retrieve data from more than one pool.

\section{Transaction costs}

Costs divide into two subsets: set-up or investment costs and ongoing or maintenance costs. The non-price costs (transaction costs) are generally difficult to measure and conceptualize, and few empirical studies have achieved any degree of success. One possible approach is to first characterize technologies according to their technical characteristics and then identify the potential transaction costs associated with the given characteristics. Apportioning costs among players needs to take this into consideration. A valid approach to co-financing of e-platforms could be to consider service costs as public or 
private economic goods. The appropriate role of each e-platform service can then be determined by the characteristics of the user information or activity. In this way it is possible to develop information communities through access code user groups that operate in overlapping dimensions of the e-platform related to product sectors, processing technologies, production systems, geographical location, marketing channels, niche markets and geo-demographic consumer groups. Two charges could be levied. First, a (relatively) fixed charge based on, for example, a percentage of turnover obtained from the platform and second, a variable charge based on actual platform usage, which could be measured in terms of number and complexity of transactions and/or frequency of access code usage.

Categorizing costs in this way allows a broader consideration of funding options for e-platforms - in particular the provision of maintenance funding is a tricky area in which responsibility is diffuse and therefore not readily adopted. Clearly, if maintenance becomes a function of leadership, then the power balance of the chain will continue to rest with larger organizations "managing" e-platforms. Therefore, consideration should be given to more diverse funding strategies, which can be seen operating in other sectors (for example in international agricultural development IFAD's methodology for evaluating the performance of systems for the delivery of animal health services www.ifad.org).

\section{Trust}

The linkages that a firm has with other players in a value chain create competitive advantages arising from relation-specific assets (specialized investments, information, language and know-how). Higher levels of trust can lead to more cooperation (joint problem solving and communication) between players and encourage producers to commit more human resources to making the chain competitive, in particular cooperation between producers can improve production planning, delivery scheduling, and quality control. In one study, knowledge-sharing, complementary resource endowments (such as collective reputation and excellent customer and supplier relationships) and effective governance strengthened the competitive edge created by differentiation and/or low-cost competitive strategies (Dyer and Singh, 1998, cited in Hardman et al., 2002).

It is not clear to what extent the SMEC model could interface with the strong retailer sector; certainly to implement such a model would require negotiation with retailers from the outset. Where the SMEC model might have advantage is in niche products where producers can aggregate around added value, such as high value meats, organic products and wine. A developed electronic trade platform can support niche markets, the special situation in which there is a small focused target group, a lot of credence qualities and intangible use-criteria, and specialized trading processes. It is thus valuable to think of multi-lateral agreements for creating common brands between several players. Assuming enterprises possess the necessary specialized skills, the best conditions for niche success are that there is sufficient buying power and potential for market growth, but the niche is not interesting for bigger competitors (Kotler, 1999, cited in llbery and Kneafsey, 1998). Best practice is to implement such solutions within an existing partnership but trust can be created if potential long term benefits such as greater market share exist and are well publicized.

To sum up we can say that the building of e-platforms in a commercially sensitive environment requires a stepwise approach as follows:

- leadership;

- active membership roles;

- strategy - common goals and transparent decision-making;

- data security;

- trust; and

- co-financing. 


\section{Research agenda emerging from the e-MENSA consultation}

In the final analysis, a preliminary consensus on the priorities for future research is presented as follows:

1. New agri-food chain management for quality and safety including:

- new technological systems for control of commodities during continuous processes, especially liquid foods;

- novel devices for shelf-life prediction in fresh produce and near-fresh processing; and

- standardization issues.

2. Provisional systems for reducing and recycling wastes.

3. New models for agri-food supply chain governance accessible to SMEs, e.g. the small and micro enterprise chain process management model.

4. Detailed cost-benefit assessments of e-collaboration in the food chain including analytical organizational studies of existing agri-food collaborative e-platforms and pilot development schemes.

Research and development at regional policy level should pay particular attention to the first link in the chain, primary producers, especially in relation to support for the implementation and ongoing management of IT resources required to build e-platforms. There is also a role for local government in the promotion of EU level agreements on quality standards and protocols.

Further information about the specific support action and continuing network activities can be obtained from r.prugger@tecnoalimenti.com

\section{References}

Brand, S., Hausen, T. and Schiefer, G. (2003), "Niche markets in the food economy and electronic trade platforms", paper presented at EFITA Conference, Debrecen, Hungary, 5-9 July.

Chevanet, C. and Landy, M. (2003), "ICTs in the European food market", IG 2 Report, Leonardo da Vinci Programme, food-MAC Network, available at: www.food-MAC.com

Düsing, C., Kamel, N.K. and Muller, D. (2003), "Product knowledge management for the extended enterprise", Abstracts ICE 2003, Espoo, Finland, 16-18 June.

Forsman, S. and Paananen, J. (2002), "Customer value creation in the short food supply chain: theoretical aspects and explorative findings", Proceedings of the 5th International Conference on Chain and Network Management in Agribusiness and the Food Industry, Paradoxes in Food Chains and Networks, Noodwijk 6-8 June, pp. 153-64.

Forzi, T., Quadt, A., Schieferdecker, R. and Stich, V. (2003), "Service provider knowledge networks enabling inter-organizational knowledge management in entrepreneurial networks", Abstracts ICE 2003, Espoo, Finland, 16-18 June.

Gray, A.W. and Boehlje, M.D. (2005), "Risk sharing and transaction costs in producer-processor supply chains", Choices, Vol. 20 No. 4, pp. 281-6.

Hardman, P.A., Darroch, M.A.G. and Ortmann, G.F. (2002), "Improving cooperation to make the South African fresh apple export value chain more competitive", Journal of Chain and Network Science, Vol. 2 No. 1, pp. 61-70.

Holt, G. and Henson, S.J. (2000), "Quality assurance management in small meat manufacturers", Food Control, Vol. 11, p. 1.

Ilbery, B. and Kneafsey, M. (1998), "Product and place: promoting quality products and services in the lagging rural regions of the European Union", European Urban and Regional Studies, Vol. 5 No. 4, pp. 329-41.

Kretzschmar, U. (2005), "First Delphi expert survey of organic food processing in 13 European countries", QLIF news, April, available at: www.qlif.org/qlifnews/april05/res1.html

London School of Economics (LSE) (2004), Investigation of the Determinants of Farm-Retail Price Spreads, London School of Economics, London. 
MacKinnon, A. and Forster, M. (2000), European Logistical and Supply Chain Trends: 1999-2005, TRILOG-Europe, Logistics Research Centre, Heriot-Watt University, Edinburgh.

Poon, S. (1999), "The nature of goods and Internet commerce benefit: a preliminary study", paper presented at 32nd Hawaii International Conference on System Sciences, IEEE, Hawaii.

Sporleder, T.L., Jackson, C.C. and Bolling, D. (2005), "Transitioning from transaction-based markets to alliance-based chains: implications for firms", Choices, Vol. 20 No. 4, pp. 275-80.

Thomas, B., Sparkes, A., Brooksbank, D. and Williams, R. (2002), "Social aspects of the impact of information and communication technologies in agri-food SMEs in Wales", Outlook on Agriculture, Vol. 31 No. 1, pp. 35-41.

Wilson, T.P. and Clarke, W.R. (1998), "Food safety and traceability in the agricultural supply chain", Proceedings of the 3rd International Conference on Chain Management in Agribusiness and the Food Industry, 28-29 May, pp. 667-75.

Wysocki, A.F. (2005), "A frictionless marketplace operating in a world of extremes", Choices, Vol. 20 No. 4, pp. 263-8.

\section{Further reading}

Department for Environment, Food and Rural Affairs (DEFRA) (2006), Food Industry Sustainability Strategy: Final Regulatory Impact Assessment, HMSO, London.

Garcia, M., Henchion, M., Holt, G.C., Reynolds, C. and Cowan, C. (2006), "Emerging electronic technologies for collaborative European agri-food supply chains", technical working paper, 1 February, e-MENSA [EC SSA 007124 e-platform Technologies for the European Agri-food Supply Chain] Tecnoalimenti S.C.p.A., Milan, Italy.

Reynolds, C., Holt, G.C., Henchion, M. and Cowan, C. (2006), "Overview of the institutional and legal framework for collaborative and inclusive e-platforms in agri-food supply chains", technical working paper, 2 March, e-MENSA [EC SSA 007124 e-platform Technologies for the European Agri-food Supply Chain] Tecnoalimenti S.C.p.A., Milan, Italy.

\section{About the authors}

G.C. Holt is a Consultant Researcher at food-etc.co.uk, Reading, UK. G.C. Holt is the corresponding author and can be contacted at: gc_holt@btinternet.com

M. Henchion is based at Teagasc, Ashtown Food Research Centre, Ashtown, Dublin, Ireland.

C. Reynolds is based at Teagasc, Ashtown Food Research Centre, Ashtown, Dublin, Ireland.

B. Baviera is based at the Departamento de Transferencia de Tecnología e Información, AINIA centro tecnológico, Valencia, Spain.

$\mathrm{J}$. Calabrese is based at the Mediterranean Agronomic Institute of Bari, Valenzano Bar, Italy.

L. Contini is based at Tecnoalimenti S.C.p.A., Milano, Italy.

C. Cowan is based at Teagasc, Ashtown Food Research Centre, Ashtown, Dublin, Ireland.

T. Dowgielwicz is based at the Institute of Logistics and Warehousing, e-Economy Centre, Poznan, Poland.

C. Luscher is based at the Department of Food Biotechnology and Food Process Engineering, Berlin University of Technology, Berlin, Germany.

A. Maraglino is based at the Mediterranean Agronomic Institute of Bari, Valenzano Bar, Italy.

R. Prugger is based at Tecnoalimenti S.C.p.A., Milano, Italy.

R. Tononi is based at the ENEA Italian National Agency for New Technologies, Energy and the Environment, Rome, Italy.

To purchase reprints of this article please e-mail: reprints@emeraldinsight.com Or visit our web site for further details: www.emeraldinsight.com/reprints 